\title{
Intraoperative sedation during regional anaesthesia (Caudal epidural anaesthesia) in paediatric patients: Role of intravenous dexemedetomidine
}

\author{
Yogendra Singhal ${ }^{1}$, Udita Naithani ${ }^{2}$, Seema Partani ${ }^{3, *}$, Lalit Kumar Raiger ${ }^{4}$, Vikram Bedi ${ }^{5}$ \\ ${ }^{1}$ Assistant Professor, ${ }^{2,3,4,5}$ Professor, Dept. of Anaesthesia, ${ }^{1,2,4,5}$ RNT Medical College Udaipur, Rajasthan, ${ }^{3}$ Geentanjali Medical \\ College, Udaipur, Rajasthan, India \\ *Corresponding Author: Seema Partani \\ Email: partaniseema@yahoo.in
}

Received: $21^{\text {st }}$ May, 2018

Accepted: $29^{\text {th }}$ June, 2018

\begin{abstract}
Introduction: To avoid adverse effects of general anaesthesia, regional anaesthesia (RA) techniques are increasingly being practiced in children for different surgeries. These RA techniques are often combined with moderate degree of sedation to remain child calm and immobile.

With limited literature available, we planned a prospective study to evaluate the effectiveness of dexemedetomidine as an intraoperative sedative agent with RA considering its short term sedation and least respiratory depression property.

Materials and Methods: Fifty children of 1-8 year of age, ASA grade 1\&2 undergoing below umbilical surgery under RA (caudal epidural anaesthesia) were selected and studied. After giving Inj. Ketamine $(1 \mathrm{mg} / \mathrm{kg})$ intravenously, RA was performed with Inj. Bupivacaine. Then inj. Dexemedetomidine $(1 \mathrm{mcg} / \mathrm{kg})$ IV was administered as bolus over 10 min followed by continuous infusion $(0.4 \mathrm{mcg} / \mathrm{kg} / \mathrm{hr})$ till completion of surgery. Perioperative sedation score, vital parameters, peripheral oxygen saturation, respiratory rate and surgeon's satisfaction were observed. The Study was considered complete till stay of patient in PACU for 2 hrs. Recovery time and any complications were noted.

Results: The quality of sedation and surgeon's satisfaction were good in all children except three children who needed extra dose of sedative. The only adverse effects reported were bradycardia and hypotension in 3 patients which were well managed by reducing the infusion rate.

Conclusion: Dexemedetomidine offers an adequate level of sedation in most of the children without haemodynamic or respiratory side effects when used intraoperatively with RA.
\end{abstract}

Keywords: Dexemedetomidine, Ketamine, Regional anaesthesia, Caudal epidural anaesthesia.

\section{Introduction}

Regional anaesthesia (RA) techniques are increasingly being practiced in children for anaesthesia and post operative pain management, as they avoid side effects associated with general anaesthesia (GA). Caudal epidural anaesthesia is a commonly used RA technique for surgeries below umbilical region in paediatric population. But it warrants the use of deep sedation or GA to achieve continuous immobility throughout surgery as paediatric patients cannot be considered cooperative. Therefore, RA is generally combined with an inhalational or intravenous technique which may require the use of an airway device.

Drugs that have been commonly used for sedation in children include midazolam, ketamine and propofol. Recently dexemedetomidine has drawn an attention for providing sedation in children due to its haemodynamic and respiratory stability properties

Dexemedetomidine is a highly selective alpha-2 receptor agonist, whose action at the local ceruleus is responsible for its anxiolytic and sedative effects while its analgesic effect is mediated through alpha -2 receptors in the dorsal horn of the spinal cord. ${ }^{1}$

Dexemedetomidine is widely used for sedation in adult population, but in paediatric patients such data are sparse. However, the studies ${ }^{1-4}$ have evaluated the sedative property of dexemedetomidine in children for sedation in the ICU, ${ }^{1}$ invasive and noninvasive procedures such as $\mathrm{MRI},{ }^{2} \mathrm{EEG},{ }^{3}$ nuclear medicine studies, cardiac catheterization, ${ }^{4}$ endoscopy,${ }^{5}$ fibreoptic intubation $^{6}$ etc. But they all studied it for procedural sedation.

The studies which show intraoperative use of dexemedetomidine in children during RA for maintenance of sedation are not widely available in literature. So we planned this study to evaluate whether dexemedetomidine can provide adequate intraoperative sedation without adverse sequel in paediatric patients undergoing infraumbilical surgeries in caudal epidural anaesthesia.

\section{Materials and Methods}

After institutional ethical committee approval, this prospective, non comparative study was conducted in paediatric anaesthesia department at RNT Medical College, Udaipur and informed parental consent was taken.

Fifty children of 1-8 years of age, ASA grade 1 and 2 of both sexes undergoing surgeries below umbilical region were enrolled and studied. Patients having congenital anomalies, cardiovascular disease, central nervous system disease, airway abnormalities and contraindications to RA (coagulopathy, local site 
infection and parental refusal) were excluded from the study.

All the patients were instructed for 6hr fasting for solid and 2 hours for water. All the resuscitation equipments and emergency drugs were kept ready for management of any adverse events.

Intranasal spray of Midazolam $(0.2 \mathrm{mg} / \mathrm{kg})$ was given to all patients in the paediatric ward. After arrival in Operation Theater, patients were canulated with two IV canula of 22 or 24 gauze; one IV line was destined for study drug infusion while other for fluid \& other medications administration. Inj Ringer lactate was started via paediatric drip set. Standard monitoring like pulse oximetry, non invasive blood pressure (NIBP) and ECG were applied. Baseline value of heart rate (HR), mean arterial pressure (MAP), oxygen saturation $\left(\mathrm{SpO}_{2}\right)$ and respiratory rate $(\mathrm{RR})$ were recorded. After complete preparation for caudal anaesthesia, patients were given Inj Glycopyrrolate $(0.004 \mathrm{mg} / \mathrm{kg})$ and $\mathrm{Inj}$ ketamine $1 \mathrm{mg} / \mathrm{kg}$ intravenously to facilitate cooperation from child to perform procedure of caudal block. Taking full aseptic precaution caudal anaesthesia was administered with 22 gauze hypodermic needle with Inj. Bupivacaine $0.25 \%$ isobaric $(1 \mathrm{ml} / \mathrm{kg})$ in lateral position.

The study drug Inj dexemedetomidine hydrochloride (Xamdex TM Abbott $100 \mathrm{mcg} / \mathrm{ml}$ ) was prepared by diluting $1 \mathrm{ml}$ of the drug with $24 \mathrm{ml}$ normal saline using $50 \mathrm{ml}$ syringe to make $4 \mathrm{mcg} / \mathrm{ml}$ concentration. Infusion (syringe) pump was used to administer dexemedetomidine $1 \mathrm{mcg} / \mathrm{kg}$ intravenously as bolus over 10 min followed by continuous infusion at the dose of $0.4 \mathrm{mcg} / \mathrm{kg} / \mathrm{hr}$ (range $0.3-0.6 \mathrm{mcg} / \mathrm{kg} / \mathrm{hr}$ to maintain sedation up to target level). Level of sedation was assessed using Ramsay sedation score $(\mathrm{RSS})^{2}$ as follows

Ramsay 1- anxious, agitated, restless

Ramsay 2- cooperative, oriented, tranquil

Ramsay 3- responsive to commands only

RSS 1-3 denotes awaken patient while RSS 4-6 are used for sleeping patients.

Ramsay 4- brisk response to light glabellar tap or loud auditory stimulus

Ramsay 5- sluggish response to light glabellar tap or loud auditory stimulus

Ramsay 6- no response to light glabellar tap or loud auditory stimulus

RSS was assessed after completion of bolus dose, then at every $15 \mathrm{~min}$ till completion of surgery, then every 30 min till post anaesthesia care unit (PACU) stay of 2 hours.

After $20 \mathrm{~min}$ of performing caudal anaesthesia, sensory blockade was checked with pinching the skin with artery forceps at incision site and surgery was allowed to start if desired level of anaesthesia and target sedation (RSS 4 or 5) was achieved. A RSS score of 4 or more was accepted satisfactory for maintenance of intraoperative sedation. Infusion rate of dexemedetomidine was adjusted according to haemodynamic response and sedation level achieved by patients.

HR, MAP, RR, $\mathrm{SpO}_{2}$ were monitored and recorded every $5 \mathrm{~min}$ for first $20 \mathrm{~min}$ then every $10 \mathrm{~min}$ till completion of surgery and then every $30 \mathrm{~min}$ till 2 hours in recovery room.

Infusion of study drug was stopped $10 \mathrm{~min}$ before completion of surgery and patients were shifted to PACU for further monitoring. Here they were monitored for 2 hours before shifting to paediatric ward. Recovery time was considered from stoppage of study drug to awakening of patients (RSS 3 or less), was also recorded. Criteria to shift from operation theatre table to PACU was achieving sedation level RSS 4 or less while it was RSS 2 or less to shift the patient from PACU to paediatric ward. Any adverse events occurred in PACU were also noted.

Inj ketamine $0.5 \mathrm{mg} / \mathrm{kg}$ was used to give rescue sedation followed by Propofol $(50 \mathrm{mcg} / \mathrm{kg} / \mathrm{min})$ if target sedation (RSS 4 or 5) was not maintained by dexemedetomidine infusion.

Surgeon was asked to rate their satisfaction with operative conditions and patients sedation using 7 point Likert verbal rating scale ${ }^{7}$ (1- extremely dissatisfied, 2dissatisfied, 3-somewhat dissatisfied, 4- undecided, 5somewhat satisfied, 6- satisfied,7- extremely satisfied).

Intraoperative hypotension was considered as $20 \%$ reduction of baseline MAP and treated by slowing the dexemedetomidine infusion rate and giving fluid bolus; bradycardia was considered as $20 \%$ reduction of baseline HR and treated with slowing dexemedetomidine infusion rate and giving Inj atropine; hypoxia ( $\mathrm{SpO} 2$ less than $90 \%$ ) was treated with supplemental oxygen by oxygen mask. If these effects persisted, infusion of dexemedetomidine was stopped and case was considered as 'failure'. Any other adverse effects if occurred were also noted.

\section{Statistical Analysis}

Continuous variables were presented as mean $\pm \mathrm{SD}$ and compared using student's t test. Data were analyzed using SPSS version 16.0 with $\mathrm{p}<0.05$ considered as statistically significant.

\section{Results}

50 paediatric patients were evaluated in the present study. Mean age and mean body weight of children were $4.02 \pm 1.58$ years (1-7 years) and $12.88 \pm 2.29 \mathrm{~kg}(8$ $20 \mathrm{~kg}$ ) respectively. All the patients were male. Types of surgeries included inguinal hernia $(n=15)$, hypospadias $(n=25)$ and orchidopexy $(n=10)$. All the patients were monitored for $\mathrm{HR}, \mathrm{MAP}, \mathrm{SpO}_{2}, \mathrm{RR}$ and RSS (1-6) at different time intervals.

Baseline mean HR was $118.76 \pm 7.16 \mathrm{bpm}$ and baseline mean MAP was $81.6 \pm 3.78 \mathrm{mmHg}$. Both were increased (Max rise of $3.33 \%$ in MAP and $4.85 \%$ in $\mathrm{HR}$ ) after $5 \mathrm{~min}$ that coincided with ketamine 
administration and then slightly decreased; after that remained stable throughout surgery. Maximum fall in mean HR was up to $97.56 \pm 4.69 \mathrm{bpm}(17.8 \%)$ while mean MAP was reduced to $67.5 \pm 3.42 \mathrm{mmHg}$ (fall $18 \%$ ), which were well within $20 \%$ of baseline. (Fig. 1, 2)

All the patients maintained $\mathrm{SpO}_{2}$ between $95-99 \%$. None of the patient showed desaturation. All the patients maintained RR according to their age.

Only 3(6\%) patients developed bradycardia intraoperatively which was successfully managed with decreasing dexemedetomidine infusion rate. These patients received supplemental sedation with ketamine $(0.5 \mathrm{mg} / \mathrm{kg})$ to achieve Ramsay score 4 .
Mean RSS after 10 min of infusion was $4.58 \pm 0.88$. It increased slightly to $4.90 \pm 0.62$ after $15 \mathrm{~min}$. Thereafter mean RSS remained 4-5 intraoperatively at all time intervals showing acceptable target sedation throughout surgery. Most of the patients maintained sedation with dexemedetomidine infusion of $0.4-0.5$ $\mathrm{mcg} / \mathrm{kg} / \mathrm{min}$. (Fig. 3)

At the time of shifting the patients from Operation Theater, the mean RSS was 3.70 \pm 0.81 .

Mean recovery time was $19.68 \pm 2.33 \mathrm{~min}$.

Mean Surgeon satisfaction score was $6.14 \pm 1.584$ implicating very high satisfaction regarding anaesthetic condition.

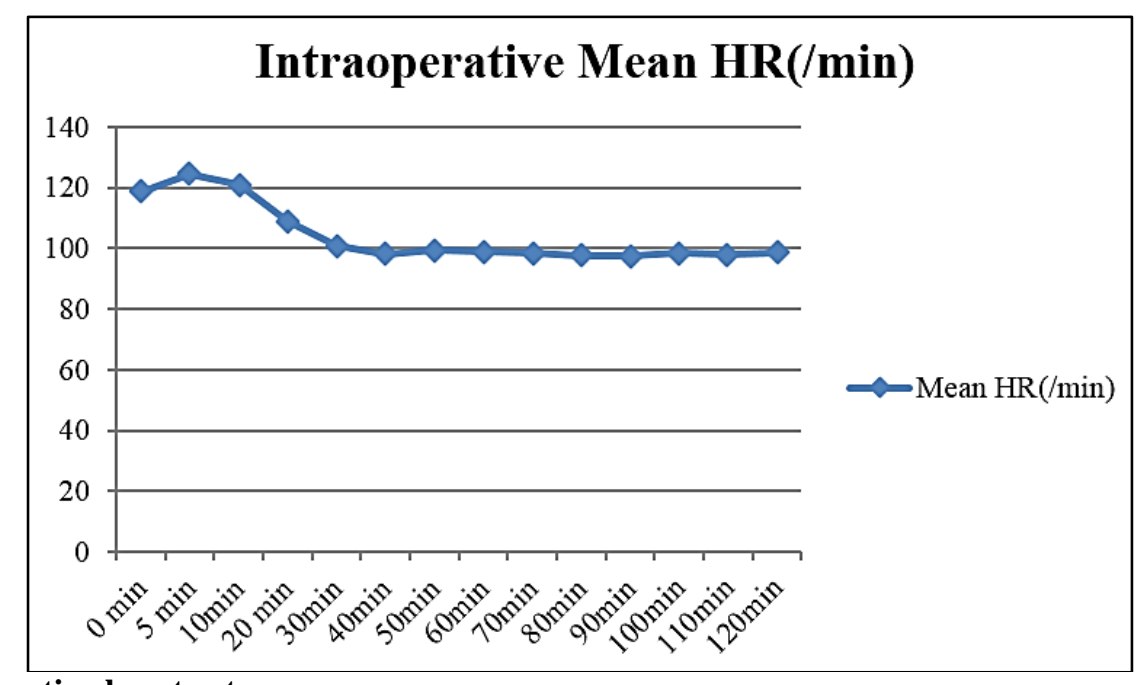

\section{Fig. 1: Intra-operative heart rate}

Fig. 1 shows intraoperative changes in mean heart rate. This depicts heart rate remained stable throughout surgery.

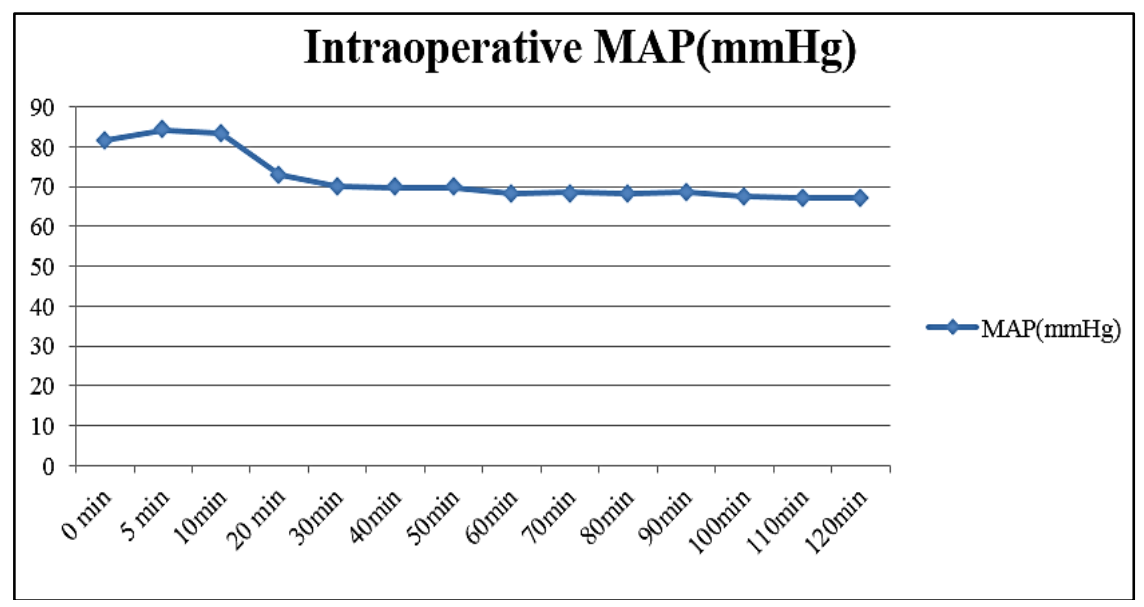

Fig. 2: Intra-operative mean arterial pressure

Fig. 2 shows intraoperative changes in mean arterial pressure. There is not statistically significant fall or rise in mean arterial pressure throughout surgery. 


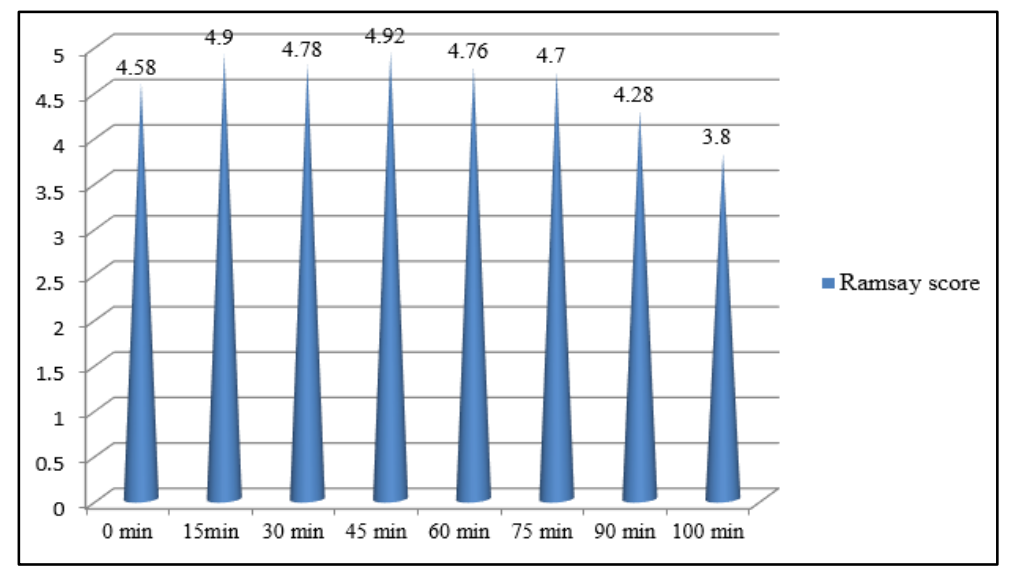

Fig. 3: Ramsay sedation score

This fig. shows sedation score in paediatric patients intraoperatively. Most of the patients maintained sedation score between 4-5 throughout surgery.

\section{Discussion}

Continuous sedation throughout procedure is a prerequisite to facilitate the surgery under regional anaesthesia in paediatric patients. By RA, we can achieve good anaesthesia and analgesia of operative field but small children cannot be expected cooperative. So continue immobility is achieved by different sedative agents.

Dexemedetomidine was approved by the United States food and drug administration (USFDA) on December 24, 1999, for the sedation in adults receiving mechanical ventilation in an intensive care setting. ${ }^{1}$ It received an additional indication for sedation of nonintubated patients prior to or during surgery or other medical procedures on October 17, 2008. ${ }^{1}$ At the recommended infusion rate, it produced the desired level of sedation in $80 \%$ of patients, without the use of additional agents. ${ }^{1}$ Since then it has been widely being used in adult population. But there are few studies available which explored its use in paediatric population $^{1-3,5}$ which have used it for noninvasive procedural like MRI, ${ }^{2} \mathrm{ICU},{ }^{1} \mathrm{EEG}^{3}$ ), procedural sedation like Cardiac catheterization, ${ }^{4}$ endoscopy, ${ }^{5}$ fibreoptic intubation $^{6}$ ) and for premedication purpose. ${ }^{8}$

Different doses of dexemedetomidine were studied. Some studies used higher dose of dexemedetomidine $e^{9,10}$ while some used standard dose of dexemedetomidine. ${ }^{2-5}$ In our study we used $1 \mathrm{mcg} / \mathrm{kg}$ as bolus dose in $10 \mathrm{~min}$ duration and then $0.4-0.7 \mathrm{mcg} / \mathrm{kg} / \mathrm{min}$ as infusion for maintenance of sedation during surgery.

In present study, most of the patients remained adequately sedated throughout the surgery. They maintained sedation score between 4-5 throughout surgery. Only 3(6\%) patients showed movement during surgery for which infusion rate of study drug was increased up to $0.7 \mathrm{mcg} / \mathrm{kg} / \mathrm{hr}$ but due to development of bradycardia, infusion rate was slowed again and supplementation was given with Inj. Ketamine to achieve target sedation RSS 4. No patient required Propofol.

Dexemedetomidine produces sedation by binding to both central and peripheral $\alpha 2$ adrenoceptors. Its sedative properties are exerted through $\alpha 2$ adrenoceptors in the local ceruleus of the pons. Binding at these G-protein receptors causes inhibition of adenyl cyclase, which in turn, decreases Cyclic AMP production, alters ion channel conductance and prevents norepinephrine release.

A. Koroglu et $\mathrm{al}^{11}$ studied sedative, haemodynamic and respiratory effects of dexemedetomidine in children undergoing magnetic resonance imaging examination. They found that $32(80 \%)$ children out of 40 children were adequately sedated during MRI examination. Here target sedation RSS 6 was prerequisite for procedural sedation. In our study incidence of adequately sedated patient was comparatively higher $(47 / 50,94 \%)$ because target sedation of RSS 4-5 was required to maintain intraoperative sedation in patients undergoing infraumbilical surgeries under caudal epidural anaesthesia. Other studies like Marcia L. Buck, ${ }^{1}$ Ashraf $S$ Hasanin et al ${ }^{12}$ also supported our results.

In present study, most of the patients remained haemodynamically stable. Mean HR and mean MAP was slightly increased after $5 \mathrm{~min}$ which could be attributed to sympahathetic effects of ketamine administration. After that HR and MAP were decreased due to the effect of dexemedetomidine. But the decrease in MAP and HR were $\leq 20 \%$ from baseline and were considered insignificant. Only $3(6 \%)$ patients developed bradycardia and hypotension. This occurred due to increasing the infusion rate to achieve desired level of sedation. But this was well managed with decreasing the infusion rate. No medication was needed to intervene. Slight haemodynamic instability was reported by Siddappa et al. ${ }^{9}$ They reported $25 \%$ decrease in bBlood pressure in $10.5 \%$ patients and $\mathrm{HR} \leq 60 \mathrm{bpm}$ in $7.9 \%$ cases with dexemedetomidine. This might be explained due to use of higher bolus dose 
$(2 \mathrm{mcg} / \mathrm{kg})$ of dexemedetomidine but other studies which used doses comparable to our study like A koroglu et al, ${ }^{11}$ Ashraf S. Hasanin et al, ${ }^{5}$ Marcia L Buck et $\mathrm{al}^{1}$ reported better haemodynamic stability which support our results.

None of the patients showed respiratory depression and decrease in respiratory rate intraoperatively in present study. This is due to dexemedetomidine does not suppress respiratory system at recommended doses. Other studies ${ }^{12,14}$ also support our results.

Post operatively none of the patients showed hypotension, bradycardia and respiratory depression. All the patients discharged to ward uneventfully in this study.

In our study recovery time was $19.68 \pm 2.33 \mathrm{~min}$. Jaydev Dave et $\mathrm{al}^{2}$ reported recovery time $26.03 \pm 9.81$ min. It was comparatively shorter in our study. It can be explained that they used higher doses of dexemedetomidine to maintain deeper level of sedation (RSS 6) as compared to our study in which lower doses were required to maintain target sedation (RSS 4-5).

In our study surgeons were highly satisfied regarding calm and immovable child.

\section{Conclusion}

We conclude that intravenous dexemedetomidine could become a reasonable option to provide intraoperative sedation in paediatric patients during surgeries being performed under regional anaesthesia. Haemodynamic stability and lack of respiratory depression are its added advantages as compared to other prevalent sedatives.

We suggest that comparative studies with a large series should be conducted in future, which compare dexemedetomidine with other sedative like Midazolam, Propofol, Sevoflurane etc. which will help us to reach on definite conclusion on this aspect.

\section{Conflicts of Interest: None.}

\section{References}

1. Marcia L. Buck, Pharm D. Dexmedetomidine use in paediatric intensive care and procedural sedation. $J$ Pediatr Pharmacol Ther. 2010;15(1):17-29.

2. Dave J, Vaghela S. A comparison of the sedative, hemodynamic, and respiratory effects of dexmedetomidine and propofol in children undergoing magnetic resonance imaging. Saudi J Anaesth. 2011;5(3):295-299. doi:10.4103/1658-354X.84105.

3. Mason KP, O'Mahony E, Zurakowski D, Libenson MH. Effects of dexmedetomidine sedation on the EEG in children. Paediatr Anaesth. 2009;19(12):1175-1183.

4. Munro HM, Tirotta CF, Felix DE, Lagueruela RG, Madril PR, Zahn EM, et al. Initial experience with dexmedetomidine for diagnostic and interventional cardiac catheterization in children. Paediatr Anaesth. 2007; 17:109-112.

5. Hasanin AS, Sirab AM. Dexmedetomidine versus propofol for sedation during gastrointestinal endoscopy in pediatric patients. Egypt J Anaesth. 2014;30(1):21-26.
6. LIU H-H, ZHOU T, WEI J-Q, MA W-H. Comparison between remifentanil and dexmedetomidine for sedation during modified awake fiberoptic intubation. Exp and Ther Med. 2015;9(4):1259-1264.

7. De Jonge A, Timmermans PBMWM, Van Zwieten PA. participation of cardiac presynaptic alpha-2 adrenoceptors in the bradycardic effects of Clonidine and analogues. Naunyn Schmiedebergs arch Pharmacol. 1981;317(1):812.

8. Peng K, Wu S, Ji F, Li J. Premedication with dexmedetomidine in pediatric patients: a systematic review and meta-analysis. Clinics. 2014;69(11):777-786. doi:10.6061/clinics/2014(11)12.

9. Siddapa R., Riggins J, Kaliyanna S., Calkins P, T. Rotta. A. high dose dexemedetomidine sedation for paediatric MRI. Paediatr Anaesth. 2011;21(2):153-158.

10. Mason K. P, Zurakowski D., Zgleszewski S. E., Robson C. D., Carrier M., Hickey P. R. and Dinardo J. A. High dose dexmedetomidine as the sole sedative for pediatric MRI. Pediatr Anesth. 2008;18:403-411. doi:10.1111/j.1460-9592.2008.02468.x

11. A. Koroglu, S Demirbilek, H. Teeksan, O. Sagir, A.K. But and M.O. Ersoy. Sedative, haemodynamic and respiratory effects of dexemedetomidine in children undergoing magnetic resonance imaging examination: preliminary results. Br J Anaesth. 2005;94(6):821-824. Doi:10.1093/bja/aei119

12. Hongbin Gu, Jie Bai and Jinfen Liu. Effect of dexemedetomidine versus Propofol on $\mathrm{Sp} 02$ in children with tetralogy of fallot during anaesthesia. Int J Clin Exp Med. 2015;8(12):22550-22556.

13. Malviya S, Voepel LT, Eldevik OP, Rockwell DT, Wong $\mathrm{JH}$, Tait AR. Sedation and general anaesthesia in children undergoing MRI and CT: adverse events and outcomes. Br J Anaesth. 2000;84:743-748.

14. Kallio A, Scheinin M, Koulu M, Ponkilainen R, Ruskoaho $\mathrm{H}$, Viinamäki O. Effects of dexmedetomidine, a selective alpha2-adrenoceptor agonist, on hemodynamic control mechanisms. Clin Pharmacol Ther. 1989;49:33-42.

15. Sun Y., Lu Y., Huang Y. and Jiang H. Is dexmedetomidine superior to midazolam as a premedication in children? A meta-analysis of randomized controlled trials. Paediatr Anaesth 2014;24:863-874. doi:10.1111/pan.12391

16. Ghali AM, Mahfouz AK, Al-Bahrani M. Preanesthetic medication in children: A comparison of intranasal dexmedetomidine versus oral midazolam. Saudi $J$ Anaesth. 2011;5(4):387-391. doi:10.4103/1658354X.87268

17. Munoz R, Berry D. Dexmedetomidine: promising drug for pediatric sedation? Pediatr Crit Care Med. 2005;6;493-494.

18. Tarek F. Tammam, Sherif S. Wahba Quality of MRI pediatric sedation: Comparison between intramuscular and intravenous dexemedetomidine. Egypt J Anaesth. 2013;29(1):47-52.

19. Shukry M., Miller JA. Update on dexemedetomidine: use in nonintubated patients requiring sedation for surgical procedures. Ther Clin Risk Manag, 2010;15:111-121.

How to cite this article: Singhal Y, Naithani U, Partani S, Raiger L. K, Bedi V. Intraoperative sedation during regional anaesthesia (Caudal epidural anaesthesia) in paediatric patients: Role of intravenous dexemedetomidine. Indian $\mathrm{J}$ Clin Anaesth. 2018;5(4):591-595. 